Journal of Engineering and Applied Sciences 14 (4): 1365-1373, 2019

ISSN: 1816-949X

(C) Medwell Journals, 2019

\title{
Performance Analysis, Pressure Drop and Phases-Distribution for Oil-Water-Air Three-Phase Flow Through Vertical Pipe
}

\author{
Isam M. Abed \\ Department of Mechanical Engineering, University of Babylon, Hillah, Iraq
}

\begin{abstract}
The present work demonstrates numerically and experiemntally the pressure drop of three-phase gasoil-water-air flow with heating process in vertical pipe. The experimental work is contain a total of 70 runs are conducted for oil flow rate with range from $0.042-0.316 \mathrm{~m} / \mathrm{sec}$ with water flow rate between 0 and $0.53 \mathrm{~m} / \mathrm{sec}$ and air velocity at range from $0.1757-0.703 \mathrm{~m} / \mathrm{sec}$. The water-phase is heating for four range of temperatures 25 , $30,35,40$ and $45^{\circ} \mathrm{C}$. The three phases flow in vertical Perspex pipe of $3.175 \mathrm{~cm}$ and overall length of $2 \mathrm{~m}$. Gasoil, water and air are used as working fluids. The flow distribution and instantaneous pressure across pipe depending on water and air-gas oil velocities and temperature of three-phase flow. The numerical model is used to obtain the fluid flow characteristic. The governing equations like continuty, momentum and energy equations are solved numerically usng finite volume method. The results indicates that the pressure drop increases with increasing the gasoil-air superficial velocities for constant water velocity, also, pressure values increases with increasing water temperature. Pressure values are higher when the velocities of air-gasoil are lower because of the temperature translation from water-phase to another two-phases are higher. Also, the pressure increases with increasing water temperature and starts to decrease with increasing concentration of other phases. Pressure, temperature, density and phases distribution along pipe.
\end{abstract}

Key words: Three-phase flow, pressure gradient, water phase temperature, vertical pipe, simulation CFD, air-gasoil

\section{INTRODUCTION}

The oil-water-air flow is very common in the petroleum industry such as oil production and pipelines flow (Govier and Aziz, 2008). The study of the pressure drop occurs during multiphase flow of fluid through pipes is more complex due to more number of variables involved. More of the previous works in this area were done when without heating process in system. These can be divided conveniently into the three-phase substances, other parameters.

Three-phase flow studied in system flowing concurrently or counter currently or in a horizontal, 90-elbow bend of $\mathrm{R} / \mathrm{d}=0.654$ ) and in inclinable (Bhaga and Weber, 1972; Spedding et al., 2008; Oddie et al., 2003). Several a ranges of gas and liquid velocities, the effects of gas, liquid flow rates and Water Liquid Ratio (WLR) and found that liquid (water and oil) thickness decreased when the gas flow rate is increased with constant liquid flow rate and increased when the liquid flow rate is increased at constant gas flow rate. Pressure drop increased when the gas and/or liquid flow rate is increased (Bhaga and Weber, 1972; Liao et al., 2007). A new measuring method of oil-water-gas three phase flow rate by using of heat transfer and fluid dynamics. The cyclone in the cylindrical used to separate the natural gas from oil-water-gas three phase mixture. The heat transfer way is used to measure water fraction with much more safety and has much more accuracy. There is no radiation in measuring. This kind of three phase flow meter used in many fields (Liao et al., 2007; Yehuda et al., 1980). The pressure drops were independent of oil viscosity (Govier et al., 1961). The flow distribution and size of droplets (Orell et al., 1971). CFD technique used to simulate the flow distribution and pressure drop (Taylor et al. 1999). The Volume of Fluid (VOF) is a suitable and more efficient model used to simulate the flow of volume one phase to another (Niegodajew et al., 2014). There are several maps of average superficial phase velocities VSL against VSG for various values of $\mathrm{f}^{\circ}$ (Yehuda et al., 1980). A model used in simulation to predict the flow pattern and the pressure drop with high accuracy (Petalas and Aziz, 2000).

The main purpose of this research is to investigate numerically and experimentally the pressure-distribution, three-phases-distribution, the effect of temperature changing on pressure along pipe and the effect of changing the velocities of gasoil-air phases flow on temperature through vertical pipe. The experimental data have been compared with three-phase experimental data of Spedding et al. (2008). 


\section{MATERIALS AND METHODS}

Experimental system: The experimental of three phase oil-water-air in vertical flow system has been built within the fluid Laboratories of the Mechanical Engineering Department at University of Babylon". The schematic diagram of the experimental setup is shown in Fig. 1. Air used as a gas phase, compressed by compressor (8) in storage (9) has capacity of $1000 \mathrm{~L}$, connected to, gas flow meter (11) of ranges (350-3500) L/h by a hose of $12.7 \mathrm{~mm}$ inner diameter. It is used to control the gas flow rate that enters the mixing pipe, gate valve (12), check valve (13) is used to prevent the inverse flow. A centrifugal pump (3) is chosen to deliver the water phase from reservoir (1) with a two heaters (7) to heated water to $(30,35,40,45)^{\circ} \mathrm{C}$, water flow rate is control by gate valve (4), check valve (5) and measured by flow meter (6), before entering in to the mixing pipe (14) by a flow meter. Centrifugal pump (16) used to supply the gasoil from tank (15), gate valve (17) and check valve (18) used to control gasoil volume flow rate. The gasoil quantity measured by flow meter (19). All phases entering a mixing pipe (14) and flowed through
Perspex pipe (20). There are five sensor (23) distributed along Perspex pipe at specific point of $0.33 \mathrm{~m}$ apart to measure pressure, all sensor connected interface device (24), personal computer (26). Eleven-channels of thermocouples (22), one of them in tank of water (1), connected to data logger (21). Accumulation tank (27) collected the mixture that leaving from Perspex pipe to by circulation pipe (25) and separate from each other. A detailed description of all components used at temperature $25^{\circ} \mathrm{C}$. The number of experiments is (100) experiment (Table 1).

\section{Experimental limetation}

Superficial velocity: It can find for every phases according to Eq. 1 (Aamir, 2015):

$$
\mathrm{Q}=\mathrm{V} \cdot \mathrm{A}_{\text {pipe }}
$$

\begin{tabular}{lcc}
\multicolumn{3}{l}{ Table 1: Properties of three-phase at $25^{\circ} \mathrm{C}$} \\
\hline Fluid & Density $\left(\mathrm{kg} / \mathrm{m}^{3}\right)$ & Dynamic viscosity $\mu(\mathrm{kg} / \mathrm{msec})$ \\
\hline Air & 1.18 & $1.81 \times 10^{5}$ \\
Water & 1000 & 0.000891 \\
Gasoil & 830 & $3.32 \times 10^{-3}$ \\
\hline
\end{tabular}

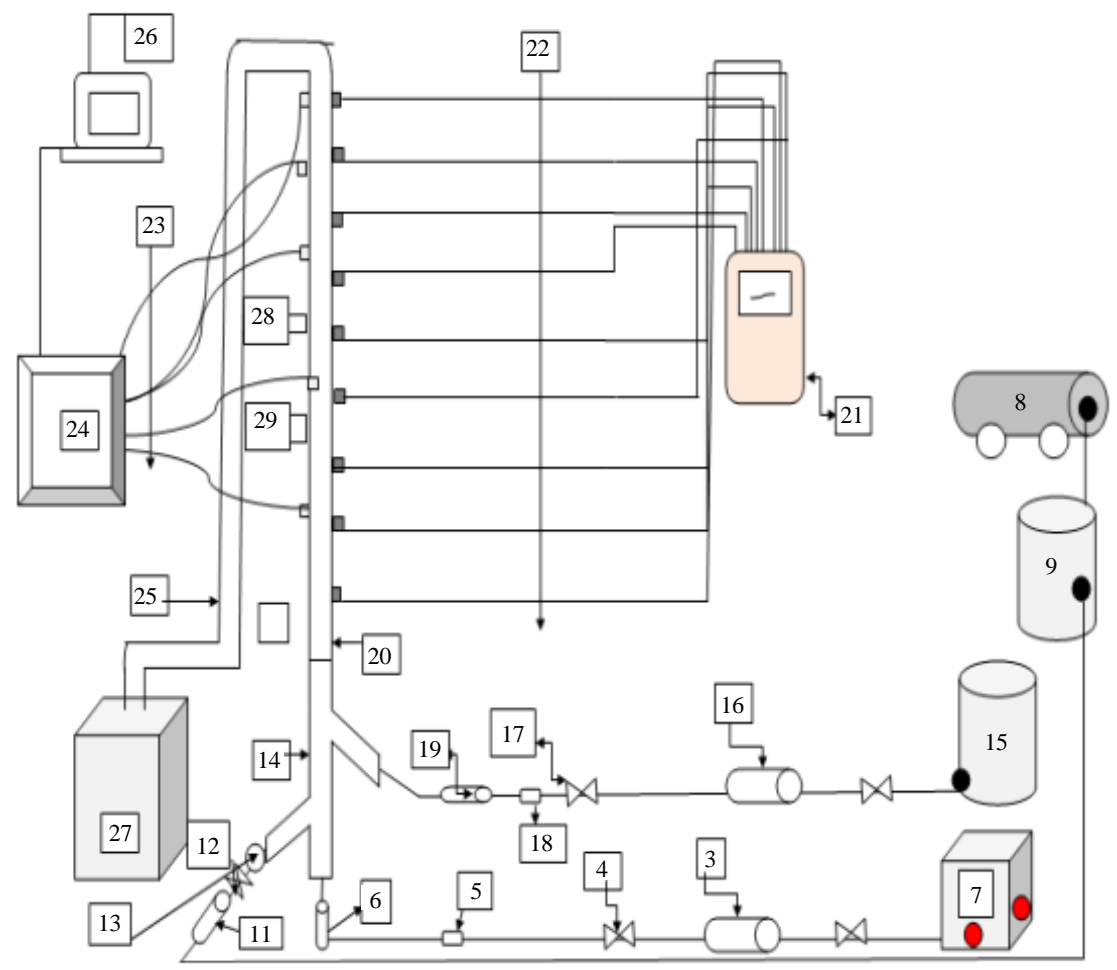

Fig. 1: Schematic-of experimental system; 1) Water's tank; 2) Thermometer; 3) Centrifugal pump; 4) Water gate valve; 5) Water check valve; 6) Water flow meter; 7) Heaters; 8) Compressor; 9) Reservior; 10) Pressure regular; 11) Air flow meter; 12) Gate valve; 13) Check valve; 14) Mixing pipe; 15) Gasoil tank; 16) Oil pump; 17) Gate valve; 18) Check valve; 19) Gasoil flow meter; 20) Perspex pipe ( $I D=1.25, \mathrm{~L}=2 \mathrm{~m}) ; 21$ ) Temperature recorder device; 22) 11 channels temperature recorder device; 23) 5 Pressure sensors; 24) Interface device; 25) Circulation pipe; 26) Personal computer; 27) Accumulation tank; 28) Ordinary video camera and 29) High speed camera 
To calculate the superficial velocity for mixture are often expressed with the help of certain mixing rules and definitions (Malhotra, 1995) as shown in Eq. 2:

$$
\mathrm{V}=\mathrm{V}_{\mathrm{so}}+\mathrm{V}_{\mathrm{sw}}+\mathrm{V}_{\mathrm{SA}}
$$

Temperature difference: The instantaneous local temperature difference at each step along the test pipe is calculate from the follow relation:

$$
\Delta \mathrm{T}=\mathrm{T}_{1}-\mathrm{T}_{10}
$$

Pressure drop calculation: The pressure across the Perspex section was measured using pressure transducer. Pressure drop for all sections can be calculated by using pressure different equations as:

$$
\Delta \mathrm{P}_{\mathrm{i}}=\mathrm{P}_{\mathrm{i}+1}-\mathrm{P}_{\mathrm{i}}, \mathrm{i}=1,2,3, \ldots
$$

Entrance length calculation: The entrance length for turbulent fully developed flow according to Cengel (2012) is given as:

$$
\mathrm{L}_{\mathrm{e}}=4.4 \mathrm{D}\left(\mathrm{R}_{\mathrm{e}}\right)^{1 / 6}
$$

So that, according to Eq. 5, the entrance length is $0.85 \mathrm{~m}$.

\section{RESULTS AND DISCUSSION}

Pressure gradient is shown in Fig. 2 and represent the instantaous pressure obtained by three-phase flow during $20 \mathrm{sec}$ for constant water velocity and gasoil and air superficial velocities for $25,35,40,45^{\circ} \mathrm{C}$. It is observed that the pressure increases with increasing temperature. It is shown the instantaous pressure as a function of time.

Figure 3-10 represent the relation between pressure and distance along the pipe for constant water velocity and constant gasoil, air velocities with various temperature $25,30,35,40,45^{\circ} \mathrm{C}$. Its noted that, the increasing pressure will drop through the pipe.

Distribution of three-phase flow in pipe: The flow distribution air-water-gasoil three-phase flow in vertical $3.175 \mathrm{~cm}$ pipe is directly digitized by using high speed camera. These images will give full description of the flow behavior in the fully developed region from the beginning of the Perspex pipe. Figure 11 shows the flow distribution (Abed and Al-Turaihi, 2013) in pipe, the water phase dominates on wall of pipe of white area while the gasoil

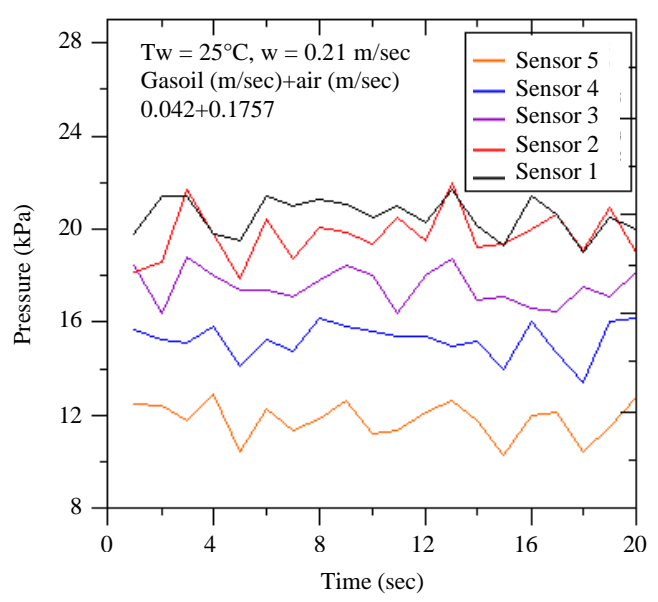

Fig. 2: Instantaneous pressure at $25^{\circ} \mathrm{C}$ water-phase temperature

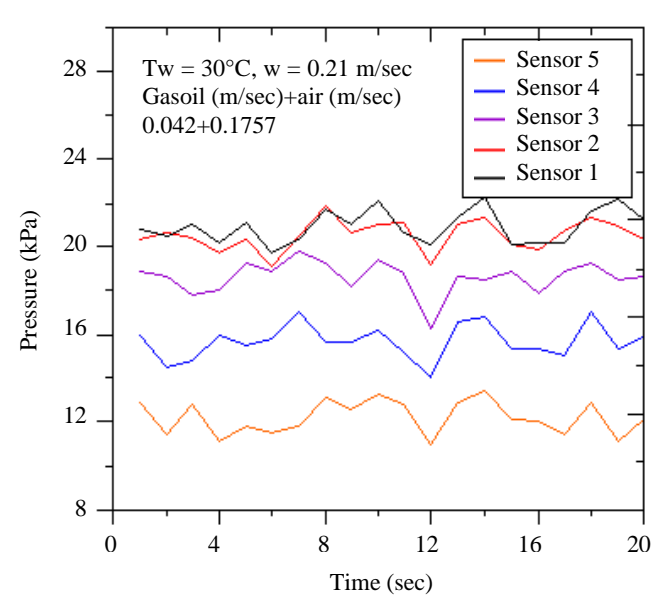

Fig. 3: Instantaneous pressure at $30^{\circ} \mathrm{C}$ water-phase temperature

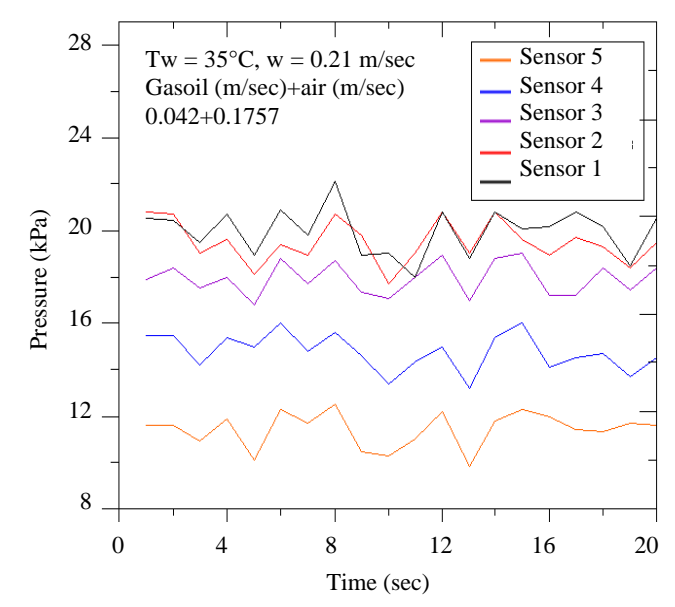

Fig. 4: Instantaneous pressure at $35^{\circ} \mathrm{C}$ water-phase temperature 


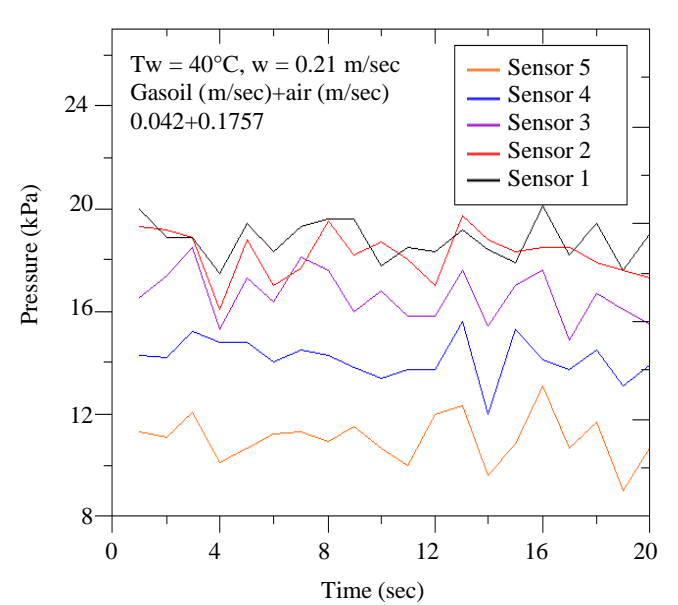

Fig. 5: Instantaneous pressure at $40^{\circ} \mathrm{C}$ water-phase temperature

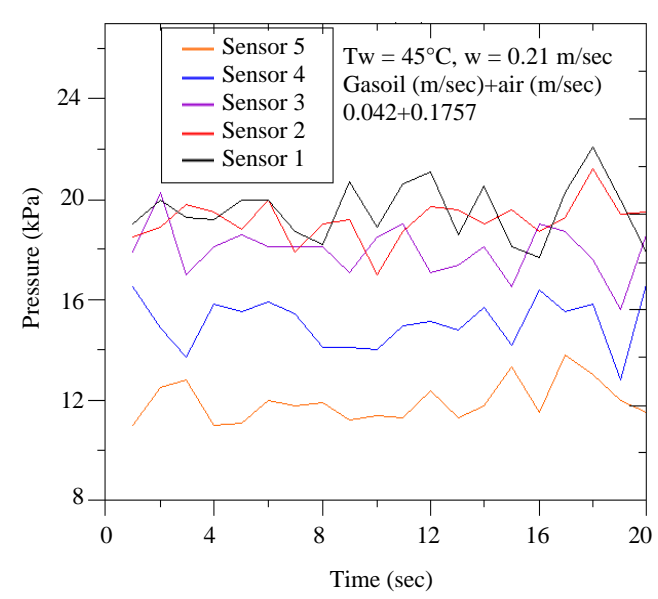

Fig. 6: Instantaneous pressure at $45^{\circ} \mathrm{C}$ water-phase temperature

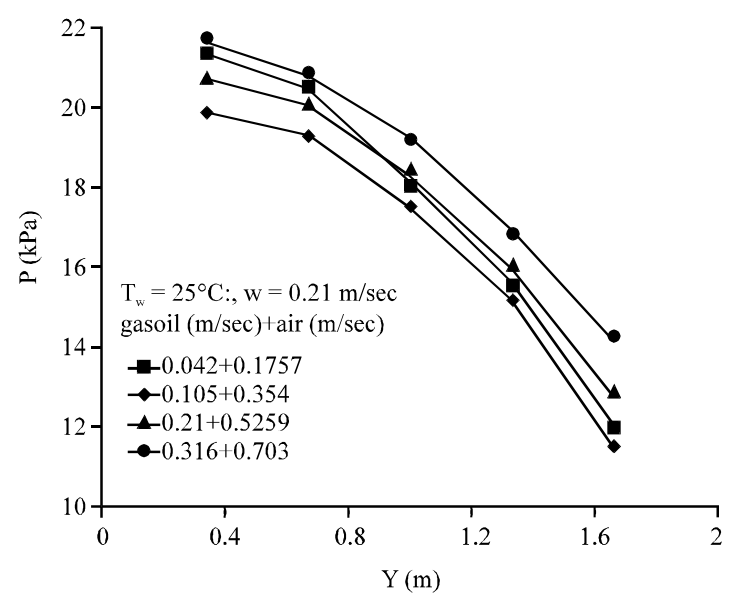

Fig. 7: Distribution pressure along distance at $25^{\circ} \mathrm{C}$ water-phase temperature

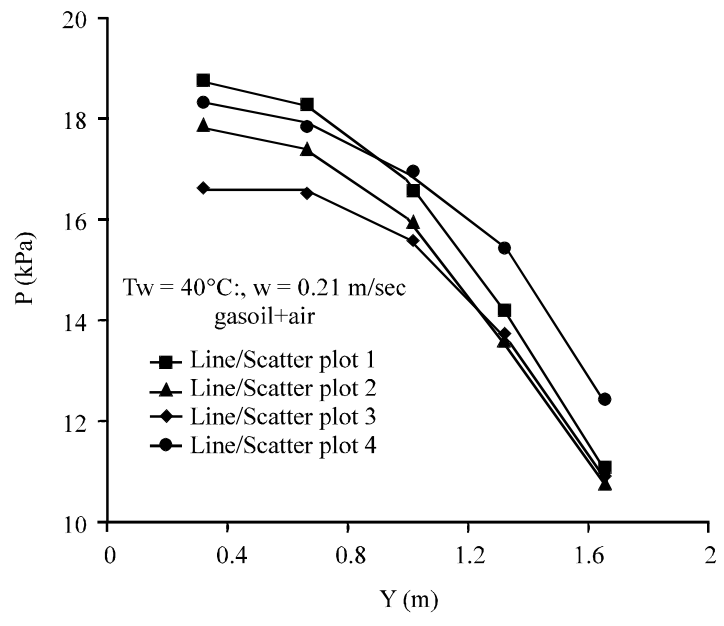

Fig. 8: Distribution pressure along distance at $35^{\circ} \mathrm{C}$ water-phase temperature

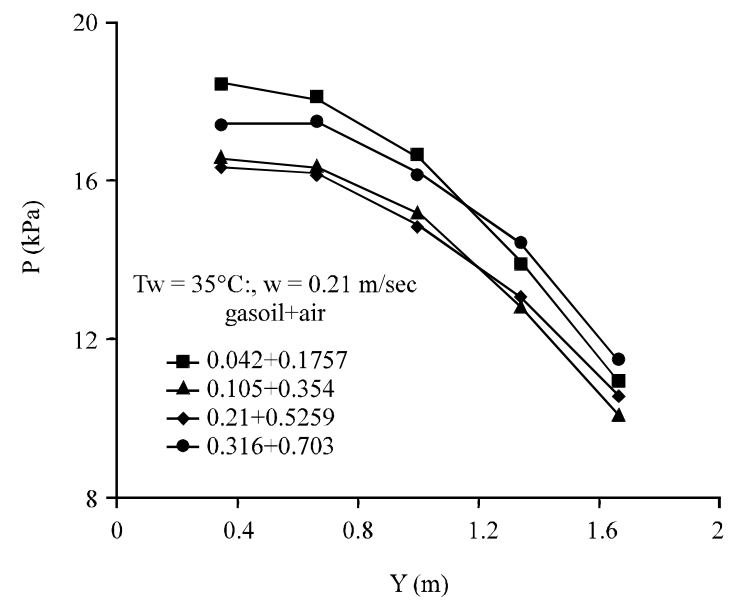

Fig. 9: Distribution pressure along distance at $40^{\circ} \mathrm{C}$ water-phase temperature

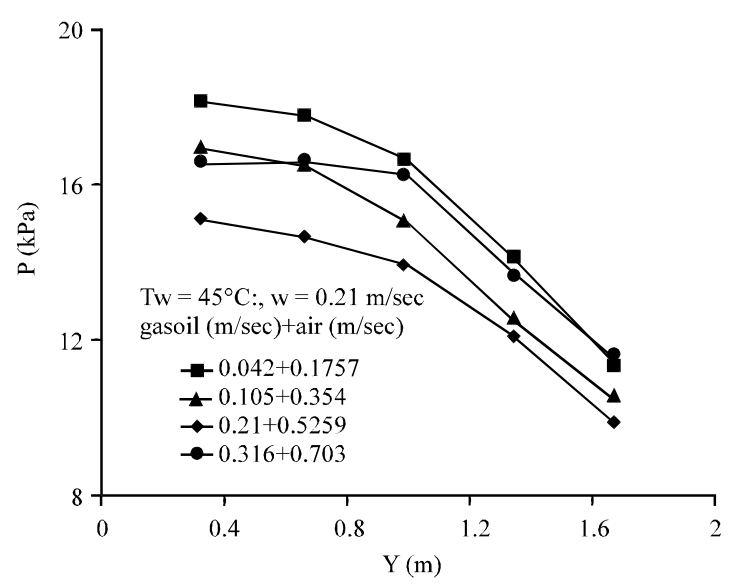

Fig. 10: Distribution pressure along distance at $45^{\circ} \mathrm{C}$ water-phase temperature 

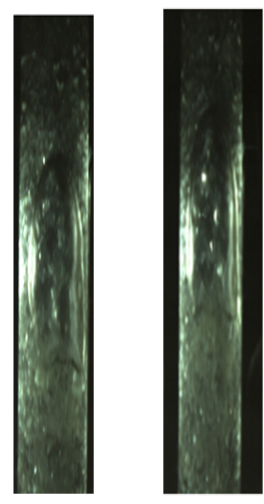

At $30^{\circ} \mathrm{C}$
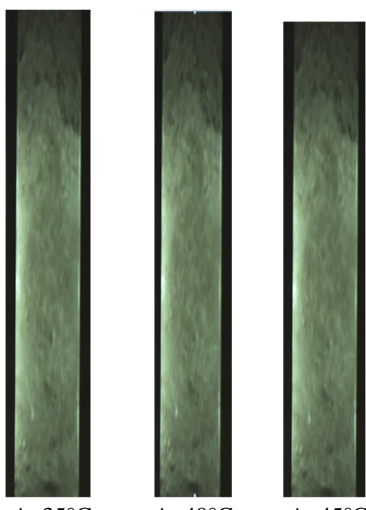

Fig. 11: Distribution of three-phase

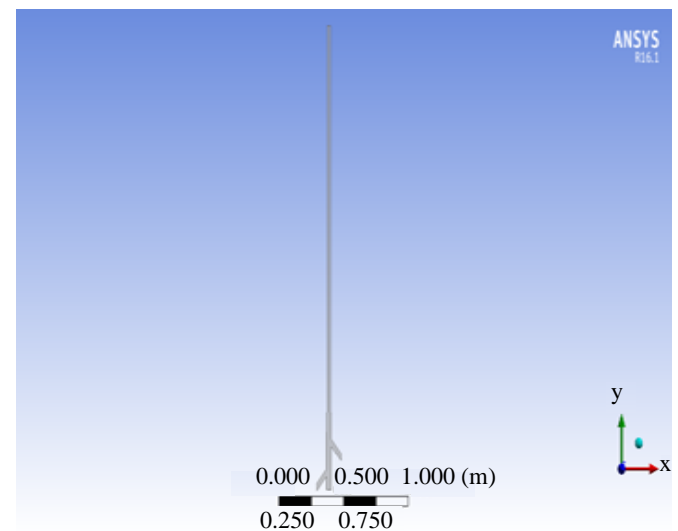

Fig. 12: Geometry and mesh of test pipe

appears in middle as a yellow areas but air-phase appears in middles as droplets of black area. At water heating, the degree of oscillatory movement moves faster due to the viscosity and density is less.

Numerical simulation: The problem of three phase flow consider steady state. This geometry details is accomplished by using ANSYS Flunt 16.1. To solve CFD problem usually consists of four main components; Geometry; Mesh generation; Setting fup a physical model; Solving it and post processing the computed data. The type of mesh depends on parameters such as flow field and geometry (Bakerd, 2006). In this resaerch, the geometry divided into small square element with ANSYS Workbenchhl 6.1 produced (4863) elements, (5914) nodes as shown in Fig. 12 and 13.

Turbulence model: To simulate this problem using VOF Model of flow with different parameters depending on the test variables and depending on the experimental results to compare and validate the CFD results. The Viscous

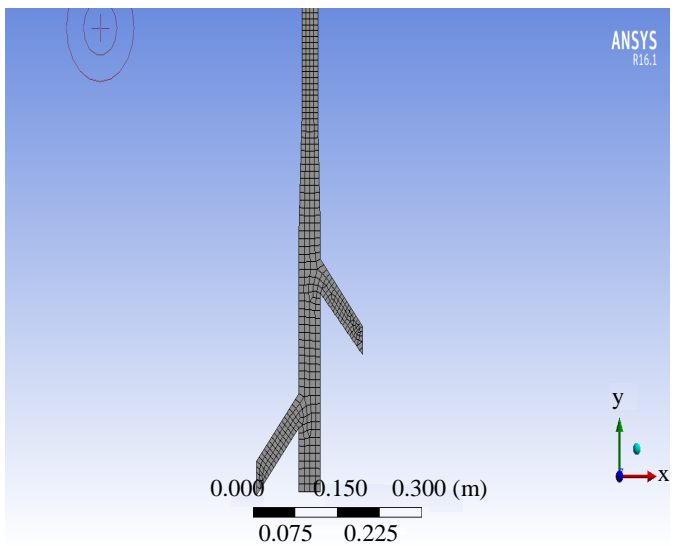

Fig. 13: Mesh of test pipe

Model is K- $\varepsilon$. K- $\varepsilon$ Model is standard and turbulence multiphase model is mixture. The assumption is that the flow is fully turbulent and the effects of molecular viscosity are negligible.

Mixture properties: The properties of component mixture that apperaring in the equations can deterimine in each control volume. $\mathrm{n}$ general for three system, all properties are calculated in same manner such as, the volume fraction averaged density, viscosity given by:

$$
\begin{aligned}
& \rho=\sum \alpha_{\mathrm{q}} \rho_{\mathrm{q}} \\
& \mu=\sum \alpha_{\mathrm{q}} \mu_{\mathrm{q}}
\end{aligned}
$$

\section{Solving equation}

Continuity equation: The continuity equation was solved for the volume fraction of the phases. The continuity equation solution is accomplished the tracking of interface between phases:

$$
\frac{1}{\rho_{\mathrm{q}}}\left(\frac{\partial}{\partial \mathrm{t}}\left(\alpha_{\mathrm{q}} \rho_{\mathrm{q}}\right)+\nabla \cdot\left(\alpha_{\mathrm{q}} \rho_{\mathrm{q}} v_{\mathrm{q}}\right)=\mathrm{S}_{\alpha_{\mathrm{q}}}+\sum_{\mathrm{p}=1}^{\mathrm{n}}\left(\mathrm{m}_{\mathrm{pq}}-\mathrm{m}_{\mathrm{qp}}\right)\right.
$$

\section{Where:}

$\rho_{\mathrm{rq}}=$ The phase reference density the subscripts

$\mathrm{q}$ and $\mathrm{p}=$ Represent the primary and secondary phases which makes $m_{p q}$ is the mass transfer from the phase $\mathrm{p}$ to the phase $\mathrm{q}$

$\mathrm{m}_{\mathrm{qp}}=$ The mass transfer from the phase $\mathrm{q}$ to the phase $p$

$\mathrm{v}, \rho_{\mathrm{q}}=$ The density of phase

$\alpha_{\mathrm{q}}=$ The volume fraction

$\mathrm{S}_{\alpha q}=$ Zero or constant or user defined mass source for each phase 
Table 2: Boundary conditions

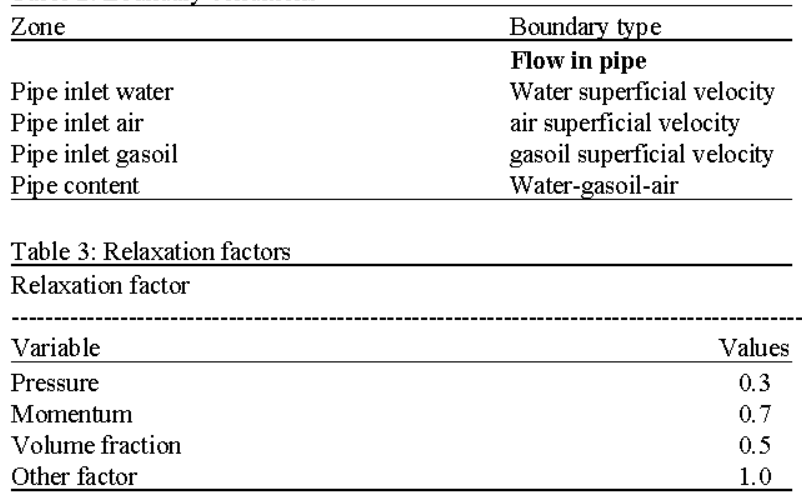

The volume fraction is calculated based on:

$$
\sum_{\mathrm{q}=1}^{\mathrm{n}} \alpha_{\mathrm{q}}=1
$$

This equation is solved by implicint time:

Momentum equation: The single momentum equation is solved:

$$
\frac{\partial}{\partial \mathrm{t}}(\rho \overrightarrow{\mathrm{v}})+\nabla \cdot(\rho \overrightarrow{\mathrm{v}} \overrightarrow{\mathrm{v}})=-\nabla \rho++\nabla \cdot[\mu(\nabla \overrightarrow{\mathrm{v}}+\nabla \overrightarrow{\mathrm{v}})]+\rho \overrightarrow{\mathrm{g}}+\overrightarrow{\mathrm{F}}
$$

Energy equation: A energy equation and shared among the phases have formed:

$$
\frac{\partial}{\partial \mathrm{t}}(\rho \mathrm{E})+\nabla \cdot(\overrightarrow{\mathrm{v}}(\rho \mathrm{E}+\mathrm{p}))=\nabla\left(\mathrm{K}_{\mathrm{eff}} \nabla \mathrm{T}\right)+\mathrm{S}_{\mathrm{h}}
$$

The VOF Model treats Energy (E) and Temperature (T) as mass averaged variables:

$$
E=\sum_{q=1}^{n} \frac{\alpha_{q} \rho_{q} E_{q}}{\alpha_{q} \rho_{q}}
$$

Boundary conditions: The boundary conditions and factors values used in simulation as shown in Table 2 and 3 . The water was set to be the primary phase and the secondary phase was the (air-gasoil). The drag function between the phases was select "Schiller-Neumann" to use the fluid-fluid drag function described in first case (Fluent User's Guide).

Set up and solution: In order to simulate the flow in pipe model, the following assumptions were made steady state, turbulent flow, 3-DN modeler and take a plane in the middle, pressure based solve, incompressible flow, the gravity in Y-direction is $\left(-9.81 \mathrm{~m} / \mathrm{sec}^{2}\right)$. The properties for the material used in the model are shown in Table 4.
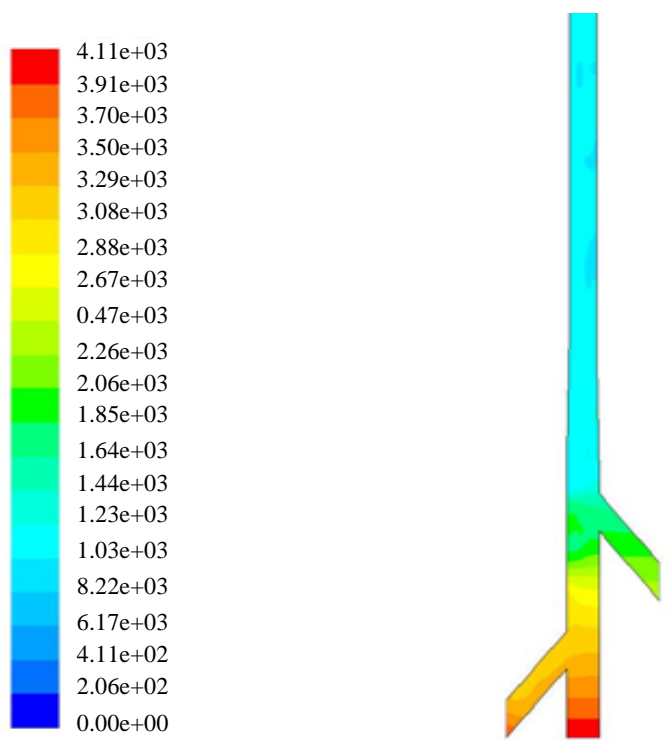

Fig. 14: Pressure-distribution at $25^{\circ} \mathrm{C}$ water-phase
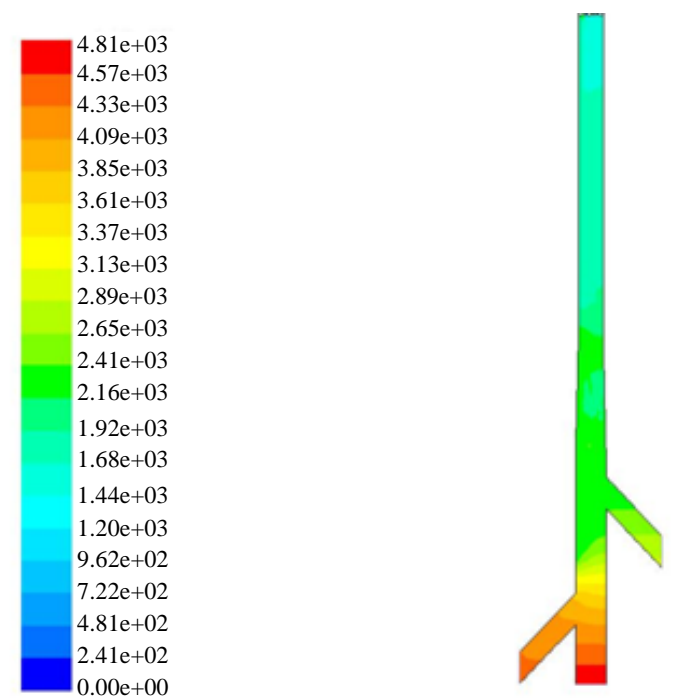

Fig. 15: Pressure-distribution at $35^{\circ} \mathrm{C}$ water-phase

Numerical results: In order to find the static pressure of mixture flow through pipe compare it with the experimental pressure sensor points were generated and the pressure was found at these points. Figure 14 and 15 represent the effect of changing temperature of water-phase $25,35^{\circ} \mathrm{C}$ on pressure, it observed that pressure values increases with temperature increasing. Figure 16-19 show the volume fraction of three-phase flow (water-gasoil-air) was used which can give a visualization of what happened inside the pipe model at $V_{\text {weter }}=0.21 \mathrm{~m} / \mathrm{sec}, V_{\text {gasoil }}=0.042 \mathrm{~m} / \mathrm{sec}$ and $\mathrm{V}_{\mathrm{ar}}=0.1757 \mathrm{~m} / \mathrm{sec}$. Figure 20 and 21 represents 


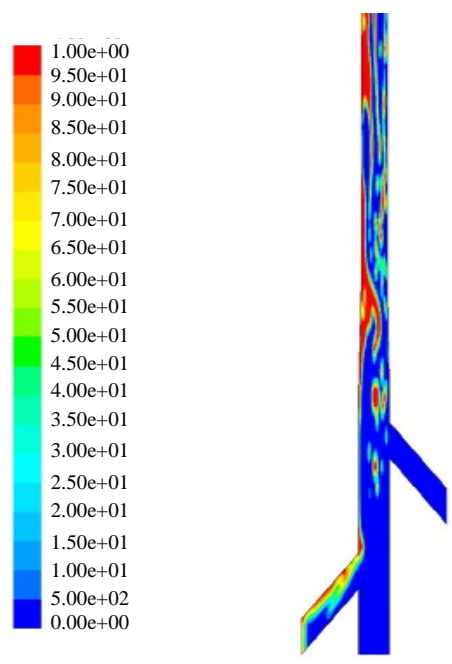

Fig. 16: Air distribution at $35^{\circ} \mathrm{C}$

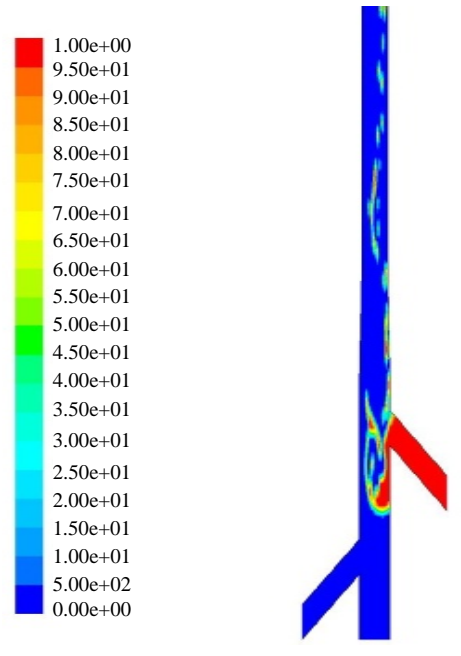

Fig. 17: Gasoil distribution at $35^{\circ} \mathrm{C}$
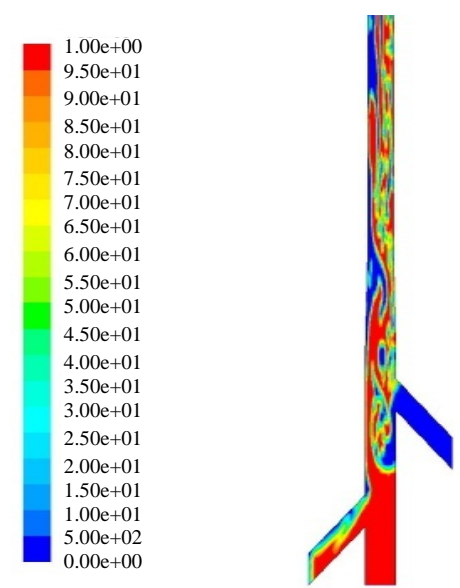

Fig. 18: Water-distributionat $35^{\circ} \mathrm{C}$

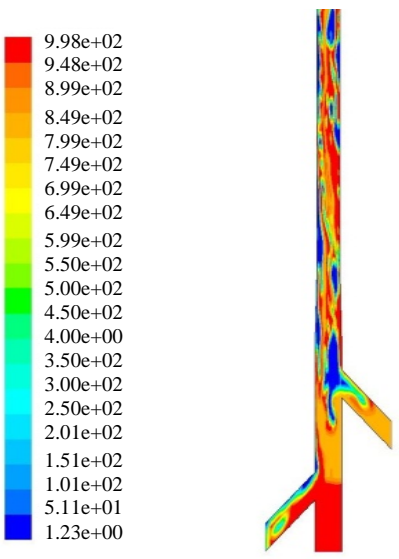

Fig. 19: Density-distribution at $35^{\circ} \mathrm{C}$

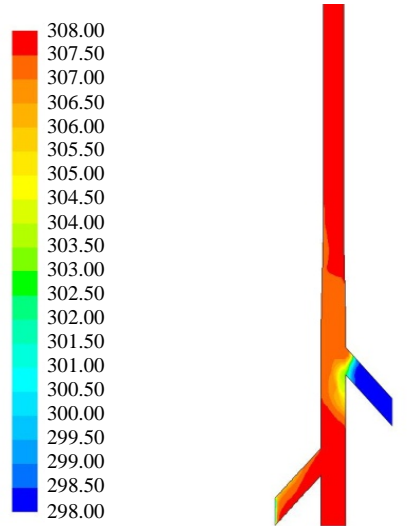

Fig. 20: Temperature-distribution at $\mathrm{T}_{\mathrm{w}}=35^{\circ} \mathrm{C} ; \mathrm{V}_{\text {wder }}=0.21$ $\mathrm{m} / \mathrm{sec}, \mathrm{V}_{\text {gasoil }}=0.042 \mathrm{~m} / \mathrm{sec}, \mathrm{V}_{\text {air }}=0.1757 \mathrm{~m} / \mathrm{sec}$

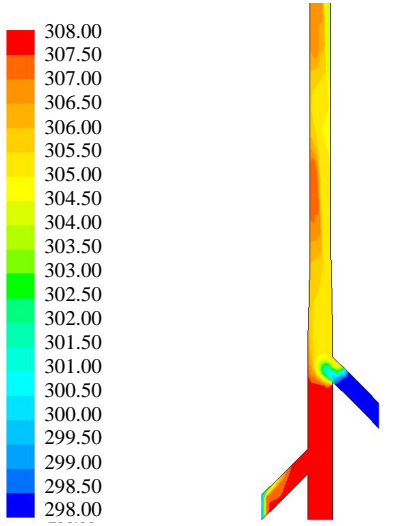

Fig. 21: Temperature-distribution at $\mathrm{T}_{\mathrm{w}}=35^{\circ} \mathrm{C}$; (b) $\mathrm{V}_{\text {wder }}=$ $0.21 \mathrm{~m} / \mathrm{sec}, \mathrm{V}_{\text {gasal }}=0.105 \mathrm{~m} / \mathrm{sec}, \mathrm{V}_{\text {air }}=0.354 \mathrm{~m} / \mathrm{sec}$

the effect of velocities changing of gasoil-air, it observed the temperature decreases with increasing the velocities of gasoil-air. 
Table 4: Properties of material

\begin{tabular}{|c|c|c|c|c|c|c|c|}
\hline \multirow[b]{2}{*}{ Prop } & \multicolumn{5}{|l|}{ Water } & \multirow[b]{2}{*}{ Air } & \multirow[b]{2}{*}{ Gasoil } \\
\hline & $25^{\circ} \mathrm{C}$ & $30^{\circ} \mathrm{C}$ & $35^{\circ} \mathrm{C}$ & $40^{\circ} \mathrm{C}$ & $45^{\circ} \mathrm{C}$ & & \\
\hline$\rho$ & 998.5 & 995.7 & 994.08 & 992.25 & 990.2 & 1.225 & 830 \\
\hline
\end{tabular}

\section{CONCLUSION}

It is observed that the pressure increases with increasing temperature. It is shown the instantaneous pressure as a function of time. Its noted that, the increasing pressure caused increases temperature and the pressure will drop through the pipe. The flow distribution in pipe, the water phase dominates on wall of pipe of white area while the gasoil appears in middle as a yellow areas but air-phase appears in middles as droplets of black area. The effect of velocities changing of gasoil-air, it observed the temperature decreases with increasing the velocities of gasoil-air. The volume fraction of three-phase flow (water-gasoil-air) was used which can give a visualization of what happened inside the pipe model. The effect of velocities changing of gasoil-air, it observed the temperature decreases with increasing the velocities of gasoil-air.

\section{NOMENCLATURE}

\begin{tabular}{|c|c|}
\hline $\mathrm{D}$ & $=$ Ipipe diameter $(\mathrm{m})$ \\
\hline $\mathrm{Vm}$ & $=$ Mixture velocity $\mathrm{i}(\mathrm{m} / \mathrm{sec})$ \\
\hline $\begin{array}{l}\text { Vwater, } \\
\text { Vgasoil, Vair }\end{array}$ & $\begin{array}{l}=\text { Superficial velocity of water, gasoil, air, } \\
\text { respectively }(\mathrm{m} / \mathrm{sec})\end{array}$ \\
\hline $\mathrm{L}$ & $=$ Length of pipe $(\mathrm{m})$ \\
\hline g & $\begin{aligned} & \text { Acceleration of gravity; Standard } \\
& \text { values }=-9.81 \mathrm{~m} / \mathrm{sec}^{2}\end{aligned}$ \\
\hline $\mathrm{P}$ & $=\operatorname{Pressure}\left(\mathrm{N} / \mathrm{m}^{2}\right)$ \\
\hline$\Delta \mathrm{P}$ & $=$ Pressure drop $\left(\mathrm{N} / \mathrm{rm}^{2}\right)$ \\
\hline $\mathrm{T}$ & $=$ Temperature $(\mathrm{K})$ \\
\hline$\Delta \mathrm{T}$ & $=$ Temperature difference $\mathrm{r}(\mathrm{K})$ \\
\hline $\mathrm{T} 1$ & $\begin{aligned}= & \text { Is the instantaneous temperature of the } \\
& \text { mixture at sensor (1) }\end{aligned}$ \\
\hline $\mathrm{T} 10$ & $\begin{aligned}= & \text { Is the instantaneous temperature of the } \\
& \text { mixture at sensor No. } 10\end{aligned}$ \\
\hline$\mu$ & $=$ Viscosity $(\mathrm{kg} / \mathrm{msec})$ \\
\hline$\rho$ & $=$ Density $\left(\mathrm{kg} / \mathrm{m}^{3}\right)$ \\
\hline Q & $=$ Liquid flow rate $\left(\mathrm{m}^{3} / \mathrm{sec}\right)$ \\
\hline A pipe & $=$ Column cross sectional area $\left(\mathrm{m}^{2}\right)$ \\
\hline $\begin{array}{l}\text { Vso, Vsw, } \\
\text { VSA }\end{array}$ & $\begin{aligned} &= \text { Superficial Velocity of gasoil, water, air } \\
& \mathrm{m} / \mathrm{sec}\end{aligned}$ \\
\hline pm & $=$ Mixture density $\left(\mathrm{kg} / \mathrm{m}^{3}\right)$ \\
\hline$\rho_{\text {gasoil }}, \rho_{\mathrm{w}}, \rho_{\text {air }}$ & $\begin{aligned}= & \text { Density of gasoil, water, air, } \\
& \text { respectively }(\mathrm{m} / \mathrm{sec})\end{aligned}$ \\
\hline
\end{tabular}

$\lambda_{\text {gasoil }}, \lambda_{\mathrm{w}}, \lambda_{\text {air }}=$ Input oil, water, air fraction

keff $\quad=$ Effective thermal conductivity

$\mathrm{Eq}=$ Specific heat of phase and the shared temperature

Sh $\quad=$ Source of volumetric heat sources

$\mu_{\mathrm{q}} \quad=$ Viscosity of phase

\section{REFERENCES}

Bakker, A., 2006. Applied computational fluid dynamics, mesh generation, computational fluid dynamics lectures. Fluent Inc., Pennsylvania, USA.

Bhaga, D. and M.E. Weber, 1972. Holdup in vertical two and three phase flow Part I: Theoretical analysis. Canad. J. Chem. Eng., 50: 323-328.

Cengel, Y.A., 2012. Heat Transfer Book. 10th Edn., McGraw-Hill, New York, USA.,

Govier, G.W. and K. Aziz, 2008. The Flow of Complex Mixture in Pipes. 2nd Edn., Society of Petroleum Engineers. Texas, USA., ISBN:9781555631390, Pages: 792.

Govier, G.W., G.A. Sullivan and R.K. Wood, 1961. The upward vertical flow of oil-water mixtures. Can. J. Chem. Eng., 39: 67-75.

Liao, H., S. Zhou, L. Liu and F. Zhou, 2007. A new measuring method of oil-water-gas three phase flowrate by using of heat transfer and fluid dynamics. AIP. Conf. Proc., 914: 221-225.

Malhotra, A., 1995. Study of two and three-phase flows in large diameter horizontal pipelines. Master Thesis, Ohio University, Athens, Ohio.

Niegodajew, P., D. Asendrych, M. Marek and S. Drobniak, 2014. Modelling liquid redistribution in a packed bed. J. Phys. Conf. Ser., 530: 1-8.

Oddie, G., H. Shi, L.J. Durlofsky, K. Aziz and B. Pfeffer et al., 2003. Experimental study of two and three phase flows in large diameter inclined pipes. Intl. J. Multiphase Flow, 29: 527-558.

Orell, D., A. Hasson and M. Finik, 1971. The study of vertical annular liquid-liquid flow: Part 1 laminar conditions. Technion-Israel Institute of Technology, Haifa, Israel. 
Petalas, N. and K. Aziz, 2000. A mechanistic model for multiphase flow in pipes. J. Canad. Pet. Technol., 39: 43-55.

Spedding, P.L., E. Benard and N.M. Crawford, 2008. Fluid flow through a vertical to horizontal 900 elbow bend III three phase flow. Exp. Therm. Fluid Sci., 32: 827-843.

Spedding, P.L., E. Benard and N.M. Crawford, 2008. Fluid flow through a vertical to horizontal 900 elbow bend III three phase flow. Exp. Ther. Fluid Sci., 32: 827-843.
Taylor, K., A.G. Smith, S. Ross and M. Smith, 1999. The prediction of pressure drop and flow distribution in packed bed filters. Proceedings of the 2nd International Conference on CFD in the Minerals and Process Industries, December 6-8, 1999, CSIRO, Canberra, Australia, pp: 273-280.

Yehuda, T., B. Dvora and A.E. Dukler, 1980. Modelling flow pattern transitions for steady upward gas-liquid flow in vertical tubes. AIChE J., 26: 345-354. 